\title{
O laser no tratamento de lesão por pressão
}

\author{
Laser in the treatment of pressure injury \\ Láser en el tratamiento de lesiones por presión
}

Recebido: 04/07/2021 | Revisado: 08/07/2021 | Aceito: 08/07/2021 | Publicado: 19/07/2021

\author{
Jaqueline Mendes Gois Santos \\ ORCID: https://orcid.org/0000-0002-2583-8868 \\ Faculdade de Irecê, Brasil \\ Jaquelinemendesj5@gmail.com \\ Ana Cristina da Silva \\ ORCID: https://orcid.org/0000-0002-4635-4045 \\ Faculdade de Irecê, Brasil \\ anacristinasilvanov@gmail.com \\ Cintia Ferreira de Amorim \\ ORCID: https://orcid.org/0000-0002-4650-8278 \\ Faculdade de Irecê, Brasil \\ cintiaferreiraamorim31@gmail.com \\ Edilson da Silva Pereira Filho \\ ORCID: https://orcid.org/0000-0002-8632-5337 \\ Faculdade de Irecê, Brasil \\ edilson.silva@faifaculdade.com.br
}

\begin{abstract}
Resumo
Objetivo: Descrever o uso do laser no tratamento de lesão por pressão mostrando seus benefícios, sua eficácia e menos tempos no reparo tecidual Método: Trata de uma revisão bibliográfica de caráter qualitativo sob revisão artigos que encontraram efeitos positivos da laserterapia a utilizando comprimentos de onda, utilizando as seguintes bases de dados para o levantamento de obras SCIELO, PubMed, os critérios de inclusão foram artigos publicados entre 2013 a 2018 em português e inglês, combinados através do operador booleano AND. Resultados e Discussão: Resulta quanto à eficácia da ação do laser como terapêutica principal na reepitelização do tecido lesionado, o sítio de aplicação do laser e lesões apresentadas pelos artigos em maior prevalência na região sacral. Além disso, o uso do laser pode ser recomendado na saúde pública e instituições privadas, possibilitando a diminuição de custos e independência aos profissionais. Conclusão: Deste modo, a laserterapia é um tratamento adjutório com ações capaz de contribuir em resolutividade acelerada, decorrente do processo de cicatrização de lesões tecidual, com evidencia na ação antiinflamatória, analgésico e cicatrizantes, onde constitui uma atuação dinâmica nos efeitos bioquímicos. Com resultados disso, o uso do laser vem trazendo um impacto positivo, proporcionando bem-estar e qualidade de vida aos clientes.
\end{abstract}

Palavras-chave: Tratamento; Laser; Lesão por pressão.

\begin{abstract}
Objective: Describe the use of laser in the treatment of pressure injuries, showing its benefits, its effectiveness and less time for tissue repair Method: This is a literature review of a qualitative nature reviewing articles on the positive effects of laser therapy when using wavelengths, using the following databases for the survey of SCIELO, PubMed works, the inclusion criteria were published between 2013 and 2018 in Portuguese and English, combined using the Boolean AND operator. Results and discussion: Results regarding the effectiveness of the laser action as the main therapy in the re-epithelialization of the injured tissue, the site of laser application and installation by the most prevalent articles in the sacral region. In addition, the use of laser can be recommended in public health and institutions, enabling the reduction of costs and independence for professionals. Conclusion: in this way, laser therapy is an adjunctive treatment with actions capable of contributing to accelerated resolution, resulting from the healing process of tissue injuries, with evidence in the anti-inflammatory, analgesic and healing action, where we form a dynamic role in the biochemical effects. As a result, the use of lasers has had a positive impact, providing well-being and quality of life to customers.
\end{abstract}

Keywords: Treatment; Laser; Pressure injury.

\section{Resumen}

Objetivo: Describir el uso del láser en el tratamiento de lesiones por presión, mostrando sus beneficios, su efectividad y menos tiempo para la reparación de tejidos. Método: Se trata de una revisión de la literatura de carácter cualitativo, 
revisando artículos sobre los efectos positivos de la terapia láser en el uso de longitudes de onda, utilizando los siguientes datos base para En la encuesta SCIELO, PubMed, los criterios de inclusión se publicaron entre 2013 y 2018 en portugués e inglés, combinados mediante el operador booleano AND. Resultados y discusión: Resultados sobre la efectividad de la acción del láser como principal terapia en la reepitelización del tejido lesionado, sitio de aplicación e instalación del láser por los artículos más prevalentes en la región sacra. Además, el uso de láser puede recomendarse en instituciones e instituciones de salud pública, lo que permite la reducción de costos y la independencia de los profesionales. Conclusión: de esta manera, la terapia con láser es un tratamiento de apoyo con acciones capaces de contribuir a la resolución acelerada, resultante del proceso de cicatrización de las lesiones tisulares, con evidencia en la acción antiinflamatoria, analgésica y cicatrizante, donde actuamos dinámicamente sobre el efectos bioquímicos. Con esto, el uso del láser tuvo un impacto positivo, brindando bienestar y calidad de vida a los clientes.

Palabras clave: Tratamiento; Láser; Lesión por presión.

\section{Introdução}

A pele é a estrutura que forma o revestimento do corpo, constituídas por fibras elásticas, colágenas, vasos sanguíneos, glândulas e nervos, dividida em epiderme, derme e hipoderme, contribuindo para proteção de eventuais patógenos, regulação de temperatura, sensibilidade e síntese de vitamina C, formando uma barreira protetora aos órgãos subjacentes, porém esse tecido pode sofrer algum rompimento de forma mecânica, através de incisões cirúrgicas, ou fisiológicas, por meio de lesões orgânicas (Thuler, 2019; Moraes, 2016).

Quando a pele sofre algum tipo de rompimento, ocorrem mudanças estruturais nos seus tecidos que podem desencadear uma lesão tecidual. Dentre esses rompimentos, destacamos a lesão por pressão (LPP), desencadeado por pressão excessiva da pele, tempo e forças de fricção e cisalhamento no local, que podem estar associados com fatores de micro clima que se refere à umidade e a temperatura da pele com a superfície de suporte, déficit nutricional pode desencadear alteração da fase inflamatória e da regeneração tecidual, a hipoperfusão que ocorre com a baixa pressão arteriolar que diminui a tolerância da pele à pressão e aumenta o risco de isquemia com complicação de pressão externa, inserções e até mesmo traumas (Mazzo, 2018; Paraixo, 2017 \& Barbosa, 2011).

A presença de uma lesão por pressão, independentemente do processo causal, ocorrerá uma série de fenômenos biológicos, que são desencadeados para que haja a reparação tecidual em busca de tratar esse trauma cutâneo. Porém, somente o mecanismo fisiológico de reparação é muito brando, principalmente de pacientes que estão debilitados com outras patologias, são necessárias medidas adicionais (coberturas especiais), que ajudam acelerar o processo de reparação e reduzir riscos de complicações (Farveto, 2017).

Dentre as possibilidades de terapias reparativas para lesão por pressão temos o tratamento convencional com terapias e coberturas, para o processo de cura do médium e longo prazo, dependendo do estágio da lesão e condição do paciente. Essa medida profilática demanda períodos prolongados para cicatrização, possibilitando danos secundários, diante disso, a ciência busca por outras opções tecnológicas aperfeiçoada. Porém ainda se constitui como um dos principais problemas de saúde pública, onde a ciência busca alternativas de tratamento e prevenção, a fim de melhorar e diminuir os índices da LPP, sendo também um fator que geram altos custos para instituições de saúde decorrente do prolongamento de internação, e para os pacientes danos físicos e psicológicos imensuráveis. Portanto, destaca-se como terapia contribuinte para o reparo tecidual o uso do laser, sendo ela incorporada no mercado atualmente (Bernardes, 2018; Mazzo, 2018; Brito 2017; Soares, 2013).

O laser Light Amplificationby Stimulated Emissionof Radiation, é uma tecnologia que emite radiação eletromagnética (REM) por um processo denominado emissão estimulada não ionizante, monocromática, infravermelho ou ultravioleta. O laser de baixa intensidade (LBI) tem uma gama de efeitos em tecidos vivos que, trata-se de uma forma de fototerapia, utilizada para induzir a produção de ATP dentro da célula, se destacando os efeitos regenerativos, anti-inflamatório e analgésico. Desse modo, o mesmo vem mostrando um forte recurso terapêutico, para a cicatrização tecidual quando utilizado pelos profissionais capacitados, com ênfase no enfermeiro que é o profissional inteiramente ligado ao paciente (Bernardes, 2018; Catorze, 2009). 
Quão importante é prevenir esse problema de saúde, cabendo ao enfermeiro e sua equipe identificar fatores de risco pendentes e implementar precauções para evitar a LPP. Os profissionais devem estar alertas a complicações associadas às lesões. Logo a assistência de enfermagem, busca o uso do laser no tratamento de LPP, onde pode ser indicada e realizada pelo mesmo. Desse modo, é necessário treinamento específico e certificações para incorporar em sua prática diária (Farveto, 2017; Tachibana, 2015).

Por fim, ao compreender que é uma tecnologia diferente na prática clínica e com muitas dúvidas referentes sua aplicabilidade e resultados, justificou a necessidade após a explanação de uma palestra com a temática e a observação nas aulas pratica, onde nos deparamos com feridas de difícil cicatrização e as limitação física que ocasiona, verificaram-se a relevância que essa temática contribui para sociedade, tendo como recurso promissor a laserterapia, mostrando-se novas opções para obtenção de melhores resultados no tratamento, contribuindo para redução do tempo de hospitalização, com isso, redução de custo e melhor utilização dos recursos do Sistema Único de Saúde (SUS), e a oportunidade de independência profissional para o enfermeiro. Para tanto, esta pesquisa teve como objetivo de descrever o uso do laser no tratamento de lesão por pressão mostrando seus benefícios, sua eficácia e menos tempos no reparo tecidual.

\section{Metodologia}

O estudo em questão trata-se de uma revisão integrativa da literatura de abordagem qualitativa. A qual determina o saber o uso do laser no tratamento de lesão por pressão. (As etapas para a revisão integrativa constituem em etapas primordiais como: 01) elaboração de uma pergunta norteadora, 02) critérios de inclusão e exclusão, 03) coleta de dados dos estudos incluídos, 04) uma análise dos estudos, 05) discussão dos resultados, 06) tendo como finalidade a revisão integrativa (Marcela, Michelly \& Rachel, 2010).

A coleta de dados foi realizada durante o período de agosto no ano de 2020, sendo considerados estudos dos últimos 9 anos. Para o levantamento dos artigos na literatura realizou-se uma busca de artigos científicos nas principais bases de indexação da saúde, através da seleção de artigos nacionais e internacionais na National Library of Medicine (PubMed), Scientific Eletronic Library Online (SCIELO). Para isto utilizou-se os seguintes descritores em saúde: A eficácia da laserterapia em lesão por pressão, efeitos da irradiação, a eficácia do uso do laser. Sendo realizado o uso dos operadores booleanos "AND" nestas bases de dados buscando artigos que abordem tais descritores. Como critérios de inclusão empregaram-se: artigos publicados entre os anos de 2013 a 2018, com os idiomas em inglês e português. Sendo que os critérios de exclusão foram: artigos que não respondiam à pergunta norteadora do estudo. Na figura 1 mostra-se a apresentação do fluxograma da busca de dados selecionados para esta pesquisa.

Figura - Fluxograma da revisão integrativa, e avaliação das buscas nas bases de dados (2021).

\begin{tabular}{|c|c|c|c|}
\hline Identificação & Estudos através da pesquisa & $\begin{array}{l}\text { SCIELO }=110 \text { PubMed }=42 \\
\text { Total }=152\end{array}$ \\
\hline Elegibilidade & Estudos excluídos após analise & $\mathrm{n}=03$ \\
\hline
\end{tabular}

Fonte: Dados de pesquisa (2021). 


\section{Resultados e Discussão}

As lesões por pressão (LPP) ainda consistem como um dos problemas de saúde que persistem durante muitos anos, principalmente no ambiente hospitalar, onde há comprometimento da segurança e da qualidade de vida do paciente. Diante disso, esses pacientes ficam expostos a riscos de complicações, resultando no aumento do tempo de internação e custos elevados para a instituição hospitalar, onde requer aplicação de coberturas específicas, essas opções de tratamento apresentam resultados eficazes, porém, com demanda de tempo grande para a cura, nos dias atuais ocorrem estudos voltados à utilização do laser em prol de resultados promissor (Dantas \& Santos, 2020; Pachá \& Faria, 2018).

Diante disso, foi realizada uma pesquisa minuciosa sobre a temática a fim de compreender os resultados da aplicação do laser e seu tempo de cicatrização na lesão por pressão. Nessa concepção, após a leitura e análise do material pesquisado conforme os critérios de elegibilidade foram agrupadas informações pertinentes acerca dos artigos encontrados, sendo 15 artigos publicados no período de 2013 a 2018, de origem nacional e internacional conforme demonstrado no Quadro 1.

Quadro 1. Características dos artigos da pesquisa.

\begin{tabular}{|c|c|c|c|}
\hline Título e autores & $\begin{array}{l}\text { Ano, } \\
\text { nacionalidade } \\
\text { dos artigos e } \\
\text { Tipo de estudo }\end{array}$ & Objetivo do estudo & Conclusão \\
\hline $\begin{array}{l}\text { Efeito da irradiação a laser em } \\
\text { diferentes comprimentos de onda ( } 940 \text {, } \\
\text { 808 e } 658 \text { nm) na cicatrização de úlceras } \\
\text { de pressão: resultados de estudo } \\
\text { clínicos. } \\
\text { TARADAJ, J.; } \text { et al. }\end{array}$ & $\begin{array}{l}2013 \\
\text { Internacional } \\
\text { Estudo clínico }\end{array}$ & $\begin{array}{l}\text { Avaliar a eficácia da terapia a laser } \\
\text { (em diferentes comprimentos de } \\
\text { onda: } 940808 \text { e } 658 \mathrm{~nm} \text { ). }\end{array}$ & $\begin{array}{l}\text { Ocorreram resultados significativos, onde } \\
\text { a diferença do comprimento de onda } \\
\text { interfere nos resultados e a efetividade na } \\
\text { ação bactericida. }\end{array}$ \\
\hline $\begin{array}{l}\text { Fechamento de úlcera crônica do } \\
\text { tornozelo e não cicatriza com terapia a } \\
\text { laser de baixa intensidade em pacientes } \\
\text { com talassemia: relato de caso. } \\
\text { AGRAWAL, S.D.P.R.; SHARMA, } \\
\text { D.K.; SINGH, R.P. }\end{array}$ & $\begin{array}{l}2014 \\
\text { Internacional } \\
\text { Relato de caso }\end{array}$ & $\begin{array}{l}\text { O possível efeito da terapia a laser } \\
\text { de baixo nível. }\end{array}$ & $\begin{array}{l}\text { Resultados significativos, com a a } \\
\text { ocorrência de resposta rápida, e redução de } \\
\text { recidivas no período de } 6 \text { meses que foi } \\
\text { analisado, um método econômico. }\end{array}$ \\
\hline $\begin{array}{l}\text { Efeito da terapia a laser na expressão de } \\
\text { fatores angios e fibrogênicos e } \\
\text { concentrações de citocinas durante o } \\
\text { processo de cicatrização de úlceras de } \\
\text { pressão humanas. } \\
\text { TARADAJ, J. et al. }\end{array}$ & $\begin{array}{l}2018 \\
\text { Internacional } \\
\text { Ensaio } \\
\text { randomizado }\end{array}$ & $\begin{array}{l}\text { Avaliar o efeito da irradiação laser } \\
\text { em diferentes comprimentos de } \\
\text { onda e o processo de cicatrização } \\
\text { das feridas. }\end{array}$ & $\begin{array}{l}\text { Resultados significativos com a utilização } \\
\text { de } 658 \text { nm de onda de comprimento e feito } \\
\text { anti-inflamatório, estimulação } \\
\text { angiogênese e remodelação. }\end{array}$ \\
\hline $\begin{array}{l}\text { Análise do tratamento com laser de } \\
\text { baixa potência em pacientes com úlcera } \\
\text { por pressão. } \\
\text { FIGUEIREDO, V.F.; } \text { et al. }\end{array}$ & $\begin{array}{l}2014 \\
\text { Nacional } \\
\text { Estudo de campo }\end{array}$ & $\begin{array}{l}\text { Analisar o tratamento com laser de } \\
\text { baixa potência em úlceras por } \\
\text { pressão infectadas, e efeitos na } \\
\text { redução e/ou inibição da carga } \\
\text { microbiana. }\end{array}$ & $\begin{array}{l}\text { Diminuição da área da lesão, redução da } \\
\text { dor e secreção da lesão. }\end{array}$ \\
\hline $\begin{array}{l}\text { Laserterapia em úlcera por pressão: } \\
\text { avaliação pelas pressures. } \\
\text { PALAGI, S.; SEVERO, } \quad \text { I.M.; } \\
\text { MENEGON, D.B.; LUCENA, A.F. }\end{array}$ & $\begin{array}{l}2015 \\
\text { Nacional } \\
\text { Relato de caso }\end{array}$ & $\begin{array}{l}\text { Descrever o processo } \text { de } \\
\text { cicatrização de úlcera por pressão. }\end{array}$ & $\begin{array}{l}\text { Ocorreu redução de quase } 6 \mathrm{~cm} \text { do } \\
\text { tamanho da lesão, aumento do tecido de } \\
\text { granulação, diminuição da secreção. }\end{array}$ \\
\hline $\begin{array}{l}\text { Aplicação de terapia fotodinâmica, } \\
\text { terapia a laser e uma membrana de } \\
\text { celulose para tratamento de úlcera de } \\
\text { pressão calcânea em um paciente } \\
\text { diabético: um relato de caso. } \\
\text { ROSA, L.P.; SILVA, F.C.; } \text { et. al. }\end{array}$ & $\begin{array}{l}2017 \\
\text { Nacional } \\
\text { Relato de caso }\end{array}$ & $\begin{array}{l}\text { Avaliar o uso do laser no } \\
\text { tratamento de úlcera por pressão } \\
\text { (UP) na região do calcâneo em } \\
\text { pacientes diabéticos. }\end{array}$ & $\begin{array}{l}\mathrm{O} \text { processo de epitelização ocorreu de } \\
\text { forma gradual no período de } 30 \text { dias. }\end{array}$ \\
\hline $\begin{array}{l}\text { Impacto da terapia a laser de baixo } \\
\text { nível na dinâmica da pressão } \\
\text { alterações induzidas por úlcera } \\
\text { considerando um agente infeccioso } \\
\text { e concentração de catelicidina LL-37: } \\
\text { um estudo preliminar. } \\
\text { BRAUNCAJS, M.; } \text { et. al. }\end{array}$ & $\begin{array}{l}2018 \\
\text { Internacional } \\
\text { Ensaio } \\
\text { randomizado. }\end{array}$ & $\begin{array}{l}\text { Investigar o impacto da terapia a } \\
\text { laser de baixa intensidade na } \\
\text { dinâmica da úlcera por pressão. }\end{array}$ & $\begin{array}{l}\text { Diante da análise, observaram colonização } \\
\text { de bactéria predominante, porém não } \\
\text { tiveram resultados significativos na } \\
\text { redução, observou efeito anti-inflamatório } \\
\text { e redução do diâmetro em } 5 \text { pacientes. }\end{array}$ \\
\hline
\end{tabular}


\begin{tabular}{l|l} 
A utilização do ultrassom terapêutico e 2015 & 2015
\end{tabular} do laser de baixa potência na Nacional cicatrização de úlcera por pressão no Estudo de caso paciente oncológico.

BARBOSA, L.; et. al.
Demonstra os efeitos da terapia No presente estudo observou-se

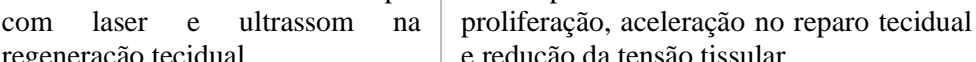
regeneração tecidual.

\begin{tabular}{|c|c|c|c|}
\hline $\begin{array}{l}\text { Efeitos do laser de baixa potência no } \\
\text { tratamento de úlceras de pressão no } \\
\text { traumatismo raquimedular: relato de } \\
\text { caso. } \\
\text { RIBEIRO, A. C.B.; et. al. }\end{array}$ & $\begin{array}{l}2017 \\
\text { Nacional } \\
\text { Estudo de caso }\end{array}$ & $\begin{array}{l}\text { Informação não disponibilizada no } \\
\text { artigo. }\end{array}$ & $\begin{array}{l}\text { Em comprimento de onda de } 904 \text {, houve a } \\
\text { regeneração tecidual da lesão por pressão e } \\
\text { redução do diâmetro em } 11 \mathrm{~cm} \text {. }\end{array}$ \\
\hline $\begin{array}{l}\text { Efeito da laserterapia na cicatrização de } \\
\text { úlcera sacral de decúbito. } \\
\text { BASTOS, L.L.S., et. al. }\end{array}$ & $\begin{array}{l}2015 \\
\text { Nacional } \\
\text { Relato de caso }\end{array}$ & $\begin{array}{l}\text { Informação não disponibilizada no } \\
\text { artigo. }\end{array}$ & $\begin{array}{l}\text { Observou no último mês, redução da área } \\
\text { de } 27 \mathrm{~cm} \text {, embora precisasse de um estudo } \\
\text { mais detalhado. }\end{array}$ \\
\hline $\begin{array}{l}\text { Efeito da laserterapia de baixa } \\
\text { intensidade sobre a cicatrização de } \\
\text { úlceras. } \\
\text { BARRETO, J. G. }\end{array}$ & $\begin{array}{l}2010 \\
\text { Nacional } \\
\text { Ensaio clínico } \\
\text { randomizado }\end{array}$ & $\begin{array}{l}\text { Analisar o tratamento com laser de } \\
\text { baixa potência em úlceras. }\end{array}$ & $\begin{array}{l}\text { Notável diminuição da área da lesão, } \\
\text { sendo feito o acompanhamento do } \\
\text { tratamento por profissionais } \\
\text { enfermagem. }\end{array}$ \\
\hline $\begin{array}{l}\text { A eficácia do laser de baixa potência na } \\
\text { cicatrização de úlcera de decúbito em } \\
\text { paciente diabético: Estudo de caso. } \\
\text { RAMOS et al A. V et al. }\end{array}$ & $\begin{array}{l}2015 \\
\text { Nacional } \\
\text { Estudo de Caso }\end{array}$ & $\begin{array}{l}\text { Verificar os efeitos da laserterapia } \\
\text { de baixa potência como } \\
\text { coadjuvante no tratamento de } \\
\text { paciente diabético com úlcera de } \\
\text { decúbito. }\end{array}$ & $\begin{array}{l}\text { Demonstrou que o efeito do laser é eficaz } \\
\text { no processo de cicatrização de úlcera de } \\
\text { decúbito em paciente diabético. }\end{array}$ \\
\hline $\begin{array}{l}\text { Efeitos dos lasers Hélio-Neônio (HeNe) } \\
\text { e Arseneto de Gálio (AsGa) associados } \\
\text { à educação em saúde com foco na } \\
\text { promoção da saúde de portadores de } \\
\text { úlcera por pressão. } \\
\text { MACHADO F. F. }\end{array}$ & $\begin{array}{l}2017 \\
\text { Nacional } \\
\text { Estudo de caso }\end{array}$ & $\begin{array}{l}\text { Comparar a ação dos lasers Hélio- } \\
\text { Neônio e Arseneto de Gálio no } \\
\text { processo cicatricial de úlceras por } \\
\text { pressão. }\end{array}$ & $\begin{array}{l}\text { Usuários que, juntamente com a } \\
\text { laserterapia, seguiram corretamente as } \\
\text { medidas preventivas obtiveram melhores } \\
\text { resultados do que aqueles que não } \\
\text { seguiram corretamente as orientações. }\end{array}$ \\
\hline $\begin{array}{l}\text { Aplicação de laserterapia em úlcera de } \\
\text { pressão em pacientes com lesão } \\
\text { medular. } \\
\text { SILVA M.C; DAYANE, S. }\end{array}$ & $\begin{array}{l}2015 \\
\text { Nacional } \\
\text { Relato de caso }\end{array}$ & $\begin{array}{l}\text { Verificar a } \\
\text { Eficácia da laserterapia no } \\
\text { tratamento de úlceras de pressão. }\end{array}$ & $\begin{array}{l}\text { A utilização do Laser no tratamento da } \\
\text { úlcera de pressão é eficaz no processo de } \\
\text { cicatrização. }\end{array}$ \\
\hline $\begin{array}{l}\text { Laserterapia na cicatrização de úlcera } \\
\text { de pressão. } \\
\text { BATISTA J.J, MOTA G.A. }\end{array}$ & $\begin{array}{l}2010 \\
\text { Internacional } \\
\text { Relato de caso }\end{array}$ & $\begin{array}{l}\text { Análise dos efeitos do laser de } \\
\text { baixa potência (AS-GA-904 nm, } \\
25 \mathrm{w} \text { ) no processo cicatricial em } \\
\text { úlcera de pressão. }\end{array}$ & $\begin{array}{l}\text { Efeitos positivos, acelerando a } \\
\text { proliferação tecidual, aumentando a } \\
\text { vascularização local e formando um tecido } \\
\text { de granulação mais organizado, } \\
\text { favorecendo uma rápida cicatrização. }\end{array}$ \\
\hline
\end{tabular}

Fonte: Dados da pesquisa (2021).

Observou-se que a maioria dos estudos consiste em relato de casos 6 artigos, onde a revisão proporcionou delineamento de 4 artigos de estudos de casos, 3 artigos de ensaio randomizados, 1 artigo de estudo de campo e 1 artigo estudo clínico. A maioria dos estudos foi publicada em português, sendo 5 em inglês e 10 em português.

Os estudos de relato de caso demonstram em peso científico que é um método de pesquisa ampla sobre um assunto específico, permitindo aprofundar o conhecimento sobre ele e, assim, ofertar obras de investigações sobre a temática. Contudo é importante ressaltar que o ensaio randomizado é considerado o delineamento padrão-ouro, pois, apresenta como vantagens; estudo minucioso, voltado a um padrão específico, com as mesmas características e um quantitativo amplo da amostra, ofertando maior precisão dos resultados, mas pressupõem desvantagens: alto custo financeiro necessita da aprovação do comitê de ética e desistência de indivíduos durante o estudo (Menezes \& Santos, 2012).

Vale ressaltar que nos estudos de relato de caso, geralmente possuem como desvantagem uma amostra pequena quando comparada a amostra de estudos randomizados. Observou-se ainda um grande número de artigos nacionais em relação aos estudos internacionais, no período de tempo estipulado na busca, que demonstra o interesse de pesquisadores nacionais na temática e também uma possível fragilidade da pesquisa em utilizar duas bases de dados internacionais SCIELO e PuBMed para a busca de artigos. 
Ao analisar as características dos estudos observou-se que os autores descrevem os resultados divididos em: classes de avaliação de efetividade da aplicação do laser, localização da LPP, comprimento de onda aplicado e efeito bactericida esperado, descritos no quadro abaixo:

Quadro 2. Categorias de avaliação para efetividade da aplicação do laser no processo de cicatrização. Sendo distribuído em ano, local da LPP, comprimento de onda, tempo de aplicação e resultados.

\begin{tabular}{|c|c|c|c|c|}
\hline $\begin{array}{l}\text { Autores e ano de } \\
\text { publicação }\end{array}$ & $\begin{array}{l}\text { Localização } \\
\text { da LPP }\end{array}$ & $\begin{array}{l}\text { Comprimento de } \\
\text { onda utilizado }\end{array}$ & $\begin{array}{l}\text { Tempo de } \\
\text { aplicação }\end{array}$ & Resultado \\
\hline RIBEIRO, A. C.B.; et al. & $\begin{array}{l}\text { Calcâneo, } \\
\text { coxofemoral, } \\
\text { sacral e } \\
\text { torácica. }\end{array}$ & $904 \mathrm{~mm}$ & $\begin{array}{l}112 \text { sessões de } \\
\text { aplicação. }\end{array}$ & $\begin{array}{l}\text { Em comprimento de onda de } 904 \text {, houve a } \\
\text { regeneração tecidual da lesão por pressão e } \\
\text { redução do diâmetro em } 11 \mathrm{~cm} \text {. }\end{array}$ \\
\hline BARRETO, J. G. & $\begin{array}{l}\text { Informação } \\
\text { não } \\
\text { disponibilizada } \\
\text { no artigo. }\end{array}$ & $632,8 \mathrm{~nm}$. & $\begin{array}{l}\text { Informação não } \\
\text { disponibilizada no } \\
\text { artigo. }\end{array}$ & $\begin{array}{l}\text { Notável diminuição da área da lesão, sendo feito } \\
\text { o acompanhamento do tratamento por } \\
\text { profissionais de enfermagem. }\end{array}$ \\
\hline RAMOS V. A; et al. & Sacral. & $670 \mathrm{~mm}$ & $\begin{array}{lrr}5 \quad \text { vezes } & \text { por } \\
\text { semana, } & \text { com } \\
\text { duração de } & 6 \\
\text { semanas. } & & \\
\end{array}$ & $\begin{array}{l}\text { O presente estudo demonstrou que o efeito do } \\
\text { laser é eficaz no processo de cicatrização de } \\
\text { úlcera de decúbito em paciente diabético. }\end{array}$ \\
\hline TARADAJ, J.; et al. & $\begin{array}{l}\text { Membros } \\
\text { inferiores. }\end{array}$ & $\begin{array}{l}\text { 940nm, } 808 \mathrm{~nm} \text { e } 658 \\
\text { nm. }\end{array}$ & $\begin{array}{l}25 \text { sessões, } 1 \text { vez } \\
\text { ao dia, } 5 \text { vezes na } \\
\text { semana durante } 1 \\
\text { mês. }\end{array}$ & $\begin{array}{l}75 \text { pacientes, dividido em } 4 \text { grupos com diferentes } \\
\text { tipos de onda, de } 940 \mathrm{~nm}, 808 \mathrm{~nm}, 658 \mathrm{~nm} \text { e um } \\
\text { placebo, com LPP em estágio II e III, por pressão } \\
\text { em membros inferiores, } 1 \text { vez ao dia, } 5 \text { vezes na } \\
\text { semana durante } 1 \text { mês, com laser de diodo, média } \\
\text { de } 4 \mathrm{~J} / \mathrm{cm}^{2} \text {. Com a utilização de } 658 \mathrm{~nm} \text {, teve } \\
47,05 \% \text { de cura, indicando maiores resultados da } \\
\text { redução do tamanho da lesão. }\end{array}$ \\
\hline ROSA, L.P.; et. al. & Calcâneo & $660 \mathrm{~mm}$ & $\begin{array}{l}30 \text { dias, aplicado } \\
2 \text { vezes na semana. }\end{array}$ & $\begin{array}{l}\text { O processo de epitelização ocorreu de forma } \\
\text { gradual no período de } 30 \text { dias. }\end{array}$ \\
\hline BASTOS, L.L.S., et. al. & Sacral. & $\begin{array}{l}\text { Laser vermelho e LED } \\
\text { azul. }\end{array}$ & $\begin{array}{l}\text { Informação não } \\
\text { disponibilizada no } \\
\text { artigo. }\end{array}$ & $\begin{array}{l}\text { Houve no último mês, redução da área de } 27 \mathrm{~cm} \text {, } \\
\text { embora precisava de um estudo mais detalhado. }\end{array}$ \\
\hline $\begin{array}{l}\text { SILVA, } \quad \text { M.C.M; } \\
\text { VERONESE, D. S. }\end{array}$ & $\begin{array}{l}\text { Informação } \\
\text { não } \\
\text { disponibilizada } \\
\text { no artigo. }\end{array}$ & $660 \mathrm{~nm}$. & $\begin{array}{l}\text { Aplicação de } 16 \\
\text { sessões. }\end{array}$ & $\begin{array}{l}\text { Apresentado uma porcentagem de melhora de } \\
89,47 \% \text {. } \\
\text { Quando comparado ao primeiro dia, logo ao } \\
\text { termino do tratamento obteve A úlcera de pressão } \\
\text { tratada nesse caso através do Laser LLT. }\end{array}$ \\
\hline TARADAJ, J.; et al. & $\begin{array}{l}\text { Sacral } \\
\text { trocanter. }\end{array}$ & $\begin{array}{l}940 \mathrm{~nm}, 808 \mathrm{~nm} \text { e } 658 \\
\mathrm{~nm} .\end{array}$ & $\begin{array}{l}1 \text { vez ao dia, } 5 \\
\text { vezes na semana } \\
\text { durante } 1 \text { mês. }\end{array}$ & $\begin{array}{l}\text { Resultados significativos com a utilização de } 658 \\
\text { nm de onda de comprimento, comparados com os } \\
\text { demais grupos. }\end{array}$ \\
\hline $\begin{array}{l}\text { BATISTA J, J; MOTA } \\
\text { G, A. }\end{array}$ & Sacral. & $904 \mathrm{~nm}$. & $\begin{array}{l}\text { Utilizado } \\
\text { sessões. }\end{array}$ & $\begin{array}{l}\text { Esse estudo mostrou efeitos positivos, acelerando } \\
\text { a proliferação tecidual, aumentando a } \\
\text { vascularização local e formando um tecido de } \\
\text { granulação. }\end{array}$ \\
\hline BRAUNCAJS, M.; et al. & $\begin{array}{l}\text { Informação } \\
\text { não } \\
\text { disponibilizada } \\
\text { no artigo. }\end{array}$ & $830 \mathrm{~nm}$. & 10 sessões. & $\begin{array}{l}\text { Diante da análise, observaram colonização de } \\
\text { bactéria predominante, porém não tiveram } \\
\text { resultados significativos na redução, observou } \\
\text { efeito anti-inflamatório e redução do diâmetro em } \\
5 \text { pacientes. }\end{array}$ \\
\hline $\begin{array}{l}\text { FIGUEREDO, V. F. et } \\
\text { al. }\end{array}$ & $\begin{array}{l}\text { Região sacral e } \\
\text { trocantérica. }\end{array}$ & $632,8 \mathrm{~nm}$. & 8 sessões. & $\begin{array}{l}\text { Diminuição da área da lesão, redução da dor e } \\
\text { secreção, alteração do aspecto dessa secreção. }\end{array}$ \\
\hline
\end{tabular}

Fonte: Dados da pesquisa (2021).

O Quadro 2, evidencia-se, categorias norteadoras, com intuito de compreender o percurso de resultados quanto à eficácia da ação do laser como terapêutica principal na reepitelização do tecido lesionado, observou-se que o sítio de aplicação tem sua maior prevalência na região sacral, visto as características intrínsecas do próprio perfil de lesão associado às condições de comprometimento da perfusão tecidual decorrente da permanência excessiva em um mesmo decúbito. Em contrapartida 
foram encontrados nesses estudos outros locais de aplicações que também proporciona resultados de regeneração, onde se salientou o fechamento de $6 \mathrm{~cm}$ em até 5 semanas, totalizando um processo de cicatrização de forma mais rápida (Thomé, et $a l, 2020)$.

Deste modo, vale ressaltar que para uma cicatrização rápida, pode existe variáveis fisiológicas que retardam esse processo de regeneração, como: idade, posicionamento, déficit no estado nutricional e remoção das eliminações, fatores esse que podem ocorrer interferência direta na redução da síntese de colágeno, fibroblastos e na angiogênese, além disso, procede um componente que os autores analisaram se contribui diretamente nos resultados, o comprimento de onda apropriado (Correia \& Resende, 2011).

Portanto, quando analisado à terapêutica com laser recomendasse avaliar a maior abrangência de variáveis, para êxito no tratamento, incluindo as do próprio equipamento. Desta maneira foi analisado pelos autores, referente ao uso dos diversos tipos de comprimento de onda utilizada na aplicação, que consiste na distância paralela, à direção em que a onda se propaga entre repetições da forma da onda, estando interligado a unidade de medida, nanômetro, que associado emitem a luz irradiada do laser com sua potencialidade. Dos estudos avaliados observou-se comprimento de ondas diferentes sendo: 632,8 nm, (Barreto, 2010); 660 nm, (Rosa, 2016); 658 nm, 808 nm, 940 nm (Taradaj, 2013), 670 nm, (Ramos, 2015), 904 nm (Ribeiro, 2017). Realizando um comparativo dos comprimentos de onda utilizados, verificou-se que o comprimento de onda entre 600 $\mathrm{nm}$ a $699 \mathrm{~nm}$ traz maiores resultados efetivo.

Diante disso, a ocorrência de radiação emitida pelo laser de baixa potência tem demonstrado efeitos analgésicos, antiinflamatório e cicatrizantes, sendo, por isso, fortemente utilizada no processo de reparo tecidual constituindo uma atuação dinâmica, abordando os efeitos de: proliferação celular e síntese de elementos constituintes da matriz extracelular, incluindo as fibras colágenas, elásticas e reticulares (Pinheiro, Almeida \& Soares 2018).

Consequentemente, o aumento do metabolismo celular ocorre através da absorção molecular da luz do laser, designado a uma estimulação de síntese de colágeno, fotorreceptores mitocondriais e alterações dos níveis de ATP. Em consideração a isso, a microcirculação sucede na pressão hidrostática capilar, com reabsorção do liquido extracelular e eliminação do acúmulo de metabólitos intermediários, função essa necessária para aumento do fluxo sanguíneo local, resultando em metabolitos fundamentais para regeneração. Portanto, a terapia a laser conduz como uma alternativa para ampliação da microcirculação (Pinheiro, Almeida \& soares 2018).

Outro efeito estudado com o uso da laserterapia é a ação bactericida promovida com a aplicação da luz sobre a lesão. Dos artigos avaliados, apenas 04 estudos avaliaram este efeito, sendo mensurado por condicionantes como: diminuição do odor, meio de cultura e efeito antiinflamatório, podendo ter um aliado para melhoria do processo infeccioso local, que é a atuação da angiogênese (Brauncajs, et al., 2018; Rosa, et al.,2016. Figueredo, et al., 2014; Taradaj, et al. 2013).

Nesse método tem destaque a angiogênese, etapa fundamental para o processo de reabilitação tecidual no qual ocorre a estimulação de novos vasos sanguíneo, que consequentemente promovera maior número de células do sistema imunitário, no combate a essa infecção. A angiogênese é um dos principais fatores do processo dinâmico do reparo tecidual, que ocorre a formação do tecido através de novos vasos sanguíneos, formados a partir de vasos preexistentes, contudo a estimulação desse fator pode corresponder cerca de $60 \%$ do tecido de reparo, sobretudo o laser quando aplicado na lesão por pressão sucede uma aceleração dos níveis de estimulação da angiogênese resultado em um aumento de suprimento de oxigênio e nutrientes para reparo da lesão e auxilio na infecção local (Neto \& Mendonça 2010; Ferreira et al, 2020).

Porem conforme os autores, o estudo da ação bactericida pode ocorrer falhas quanto ao meio de cultura dessas feridas, pois há existência de variáveis fisiológicas, que interfere comprometendo a avaliação, associado às condições propícias a proliferação das bactérias, através da contaminação da lesão, apresentando umidade e nova carga microbiana, decorrente da dependência do paciente, causando um desequilíbrio orgânico local, consequentemente a imprecisão dos resultados. Embora o 
laser apresente alguns feitos de progressão nas amostras sanguínea, havendo diminuição das interleucinas, no entanto é notável a deficiência de uma pesquisa com essa finalidade de ação (Tokuc, et al, 2019; Wang, et al, 2018).

Quando se argumenta sobre as deficiências presente nos estudos, podemos notar um déficit quanto a presença de normatizações e protocolos a fim de compreender de maneira precisa o manuseio do equipamento, que não são relatados pelos autores, onde fica evidenciado pelos diversões tipos de tempo de aplicação, distintamente, exposto no quadro 2, essa falta pode interferir na maior exatidão dos resultados, sendo assim de suma importância para as linhas de estudos e principalmente para ofertar um direcionamento adequado para o profissional que irá manusear nas diversas situações que presenciara (Thomé, 2020; Pereira \& Moreira, 2014).

De modo geral os estudos demonstram a efetividades da aplicação do laser, mas não sucedeu apresentar nenhum estudo comparativo com as terapias convencionais de cobertura para avaliação das vantagens e desvantagens da utilização. Além disso, a laserterapia retrata-se um método eficaz, havendo diminuição do tempo de cicatrização e reduzindo as complicações das LPP, sendo, de baixo custo, onde seu uso pode ser recomendado na saúde pública e instituições privadas, possibilitando independência aos profissionais (Regonha \& Rossi, 2011).

Contudo os profissionais para obter acesso ao uso do laser devem conhecer bem a fundamentação teórica, e toda funcionalidade do equipamento, nomeadamente os modos de emissão, duração, comprimento de onda e a densidade de energia. Sendo assim, a utilização desses critérios nas sessões de laserterapia possibilitará realizar um tratamento eficaz e obtenção de benefício terapêutico (Bernardes \& Jurando, 2018; Ferreira, 2016).

\section{Conclusão}

Mediante analise global do contexto em relação ao tratamento da lesão por pressão, constata-se que ainda vem sendo um dos maiores problema de saúde pública, onde o serviço de saúde ainda busca por excelência. Portanto conclui-se que a laserterapia é um tratamento adjutório com ações capaz de contribuir em resolutividade acelerada, decorrente do processo de cicatrização de lesões tecidual, com evidencia na ação antiinflamatória, analgésico e cicatrizante, onde constitui uma atuação dinâmica nos efeitos bioquímicos. Vale evidenciar se que, os resultados estão voltados ao quadro clinico do indivíduo, ocorrendo à necessidade de estudos mais específicos que buscar trazer algo mais detalhado e consequentemente com exatidão, com isso, o uso do laser vem trazendo um impacto positivo, proporcionando bem-estar e qualidade de vida aos clientes de forma segura.

Dessa forma é perceptivo que, o paramento utilizado para a aplicação do laser está voltado ao cumprimento de onda, no qual se destacou no quesito de resultados positivos, apresentado na maioria dos estudos. Embora não ocorra um consenso dos autores nos artigos analisado, quanto ao tipo de laser, quantidade de joules, frequência das aplicações, e um padrão especificam para cada situação, existindo um déficit na presença de normatizações e protocolos de manuseio, sendo viável para aquisições futuras. Portanto recomenda-se que o desenvolvimento do estudo abrangente em diferentes cenários a fim de aprimorar as evidências que envolvem o processo de cicatrização no tratamento de lesão por pressão, a demonstração de resultados satisfatórios e baixo custo com esse tratamento pode acarretar em um aumento pela temática e mais estudos a esse fim, e quando se está voltada à enfermagem oferta uma autonomia de novas opções, já que o enfermeiro se torna o protagonista dessa ação de cuidado e bem estar. Com isso ocorre a necessidade de trabalhos futuro com intuito de estabelecer diretrizes e normas.

\section{Referências}

Agrawal, T., Gupta, G. K., Rai, V., Carroll, J. D., \& Hamblin, M. R. (2014). Pre-conditioning with low-level laser (light) therapy: light before the storm. Doseresponse: a publication of International Hormesis Society, 12(4), 619-649. https://doi.org/10.2203/dose-response.14-032.Agrawal. 
Bernardes, L., \& Jurado, So (2018). Efeitos da laserterapia no tratamento de lesões por pressão: uma revisão sistemática. Rev Cuid. 2018; 9(3): 2423-34. http://dx.doi.org/10.15649/cuidarte.v9i3.574.

Bernardes, L. de O., \& Jurado, S. R. (2018). Efeitos da laserterapia no tratamento de lesões por pressão: uma revisão sistemática. Revista Cuidarte, 9(3), 24232434. https://doi.org/10.15649/cuidarte.v9i3.574.

Brito, B. (2017). Fatores de risco e indicações dermatologicas. URF, p.66.

Catorze. (2010). Fundamentos endematologia, p.23.

Chen, C., Hou, W. H., Chan, E. S., Yeh, M. L., \& Lo, H. L. (2014). Phototherapy for treating pressure ulcers. The Cochrane database of systematic reviews, (7), CD009224. https://doi.org/10.1002/14651858.CD009224.pub2.

Correia, M. \& Rezende, R. (2011, julho 15). Terapia Nutricional para portadores de úlcera por pressao. Sociedade brasileira de nutrição, p.10.

Costa, A. F., \& Assis, J. C. (2012). In vitro assessment of the bactericidal effect of low-power arsenium-gallium (AsGa) laser treatment. Anais brasileiros de dermatologia, 87(4), 654-656. https://doi.org/10.1590/s0365-05962012000400029.

Dantas, A. \& Santos, M. (2020). Prevenção e tratamento de lesão por pressão (3a ed.), Hemorio.

Ferreira, Aline Gomes Afonso (2016) Aplicação do laser de baixa intensidade no processo de cicatrização de feridas cirúrgica: padronização dos parâmetros dosimetricos. (2016), 110.

Ferreira, D. \& Batista, A. (2021). A atuação da leserteaoia na aginogeneses e o reparo tecidual. Research society qnd Developmet, $10(3), 12$.

Machado, R. S., Viana, S., \& Sbruzzi, G. (2017). Low-level laser therapy in the treatment of pressure ulcers: systematic review. Lasers in medical science, 32(4), 937-944. https://doi.org/10.1007/s10103-017-2150-9

Mendonça, Ricardo. \& Netto, Joaquim. (2010, agosto 12). Aspectos celulares da cicatrização. Revisao, p.6.

Menezes, A., \& Santos, I. (2012). Epidemiologia básica para pneumologista. Ufipel, 3(28533), 3.

Moraes, R. (2016). Conceito de classificação de lesão por pressão. NPUAP, p.12.

Pachá, H. \& Faria, J. (2018). Lesão por pressão em unidade de terapia intensiva. REBEn, 6(3201), 8.

Paraizo. (2017). V. Recuperado de https://amwricancansamed.com.br.

Parker S. (2007). Verifiable CPD paper: introduction, history of lasers and laser light production. British dental journal, 202(1), 21-31. https://doi.org/10.1038/bdj.2006.113.

Pereirra, A., \& Morreira, M. (2014). Laser r em baixa intensidade pode estimular o processo aginogeneses. Ciência Saúde, 4(1521),7.

Pinheiro, A., Almeida, P., \& Soares, L. (2018). Princípios fundamentais dos lasers e suas aplicações. https://www.researchgate.net/publication/313492 693_Principios_fundamentais_dos_lasers_e_suas_aplicacoes.

Ragonha, A. \& Rossi, L. (2010). Avaliação microbiológica de coberturas. Latino am enfermagem, 1(51421), 8.

Soares, P. F.; Dayne, R. J.; Silva, M.; Beatriz, O.; Souza, S.; Danski, R.; Tannia, M.; Meier, M. J. Algoritmo de prevenção e tratamento de úlcera por pressão. Cogitare Enfermagem, 18(2), 238-244 Universidade Feder do Paraná Curitiba.

Tachibana, T., Imafuku, S., Irisawa, R., Ohtsuka, M., Kadono, T., Fujiwara, H., Asano, Y., Abe, M., Ishii, T., Isei, T., Ito, T., Inoue, Y., Ohtsuka, M., Ogawa, F., Kodera, M., Kawakami, T., Kawaguchi, M., Kukino, R., Kono, T., Sakai, K., \& Wound/Burn Guidelines Committee (2016). The wound/burn guidelines 2: Guidelines for the diagnosis and treatment for pressure ulcers. The Journal of dermatology, 43(5), 469-506. https://doi.org/10.1111/1346-8138.13274.

Tavarez, M., Mycheli \& Silva, M. (2010, dezembro 12). Revisão integrativa: o que é e como fazer. Einstein, p.5.

Thomé Lima, A., da Silva Sergio, L. P., da Silva Neto Trajano, L. A., de Souza, B. P., da Motta Mendes, J. P., Cardoso, A., Figueira, C. P., Dos Anjos Tavares, B., Figueira, D. S., Mencalha, A. L., Trajano, E., \& de Souza da Fonseca, A. (2020). Photobiomodulation by dual-wavelength low-power laser effects on infected pressure ulcers. Lasers in medical science, 35(3), 651-660. https://doi.org/10.1007/s10103-019-02862-w.

Tokuc, M., Ozalp, S., Topcuoglu, N., \& Kulekci, G. (2019). Bactericidal Effect of $2780 \mathrm{~nm}$ Er,Cr:YSGG Laser Combined with $940 \mathrm{~nm}$ Diode Laser in Enterococcus faecalis Elimination: A Comparative Study. Photobiomodulation, photomedicine, and laser surgery, 37(8), 489-494. https://doi.org/10.1089/photob.2018.4613.

Wang, X., Cheng, X., Liu, X., Wang, Z., Wang, J., Guo, C., Zhang, Y., \& He, W. (2018). Bactericidal Effect of Various Laser Irradiation Systems on Enterococcus faecalis Biofilms in Dentinal Tubules: A Confocal Laser Scanning Microscopy Study. Photomedicine and laser surgery, 36(9), 472-479. https://doi.org/10.1089/pho.2017.4430. 